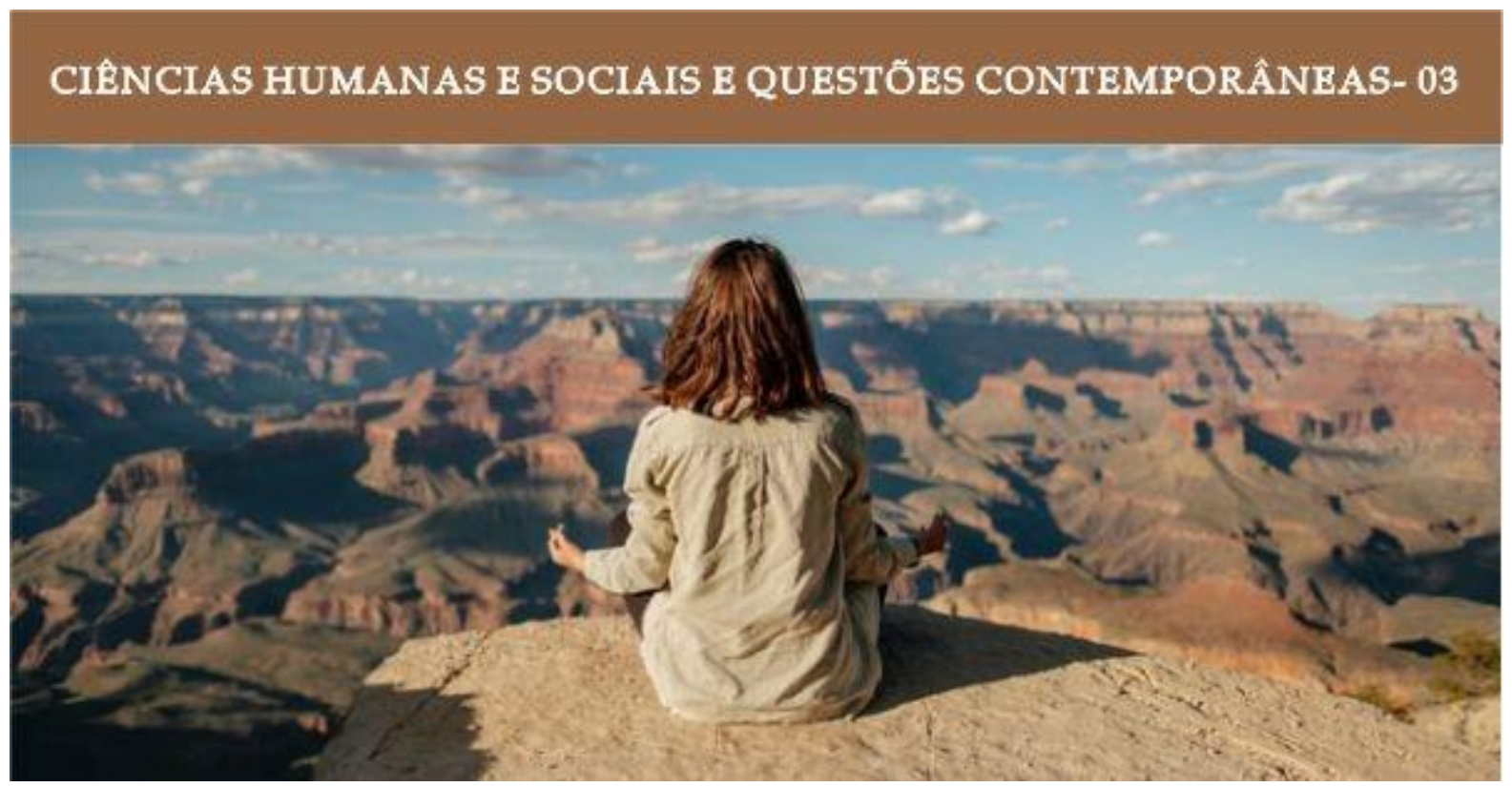

\title{
TEORIA DO APEGO E MEDITAÇÃO DA (AUTO)COMPAIXÃO: COMO A SUA PRÁTICA PODE AFETAR A FORMA DE SE RELACIONAR COM O OUTRO?
}

\author{
Alice Bruzzi Herkenhoff \\ ORCID: https://orcid.org/0000-0002-6671-6840. \\ E-mail: alice@psimples.psc.br. \\ Luciana Fontes Pessôa \\ ORCID: https://orcid.org/0000-0002-4446-4283. \\ E-mail:pessoalf@gmail.com.
}

Resumo: O presente artigo procura, por meio de uma revisão bibliográfica, entender se a prática da meditação da compaixão pode ser uma ferramenta útil para alcançar um estilo de apego seguro. A busca pelo último se justifica por corroborar com um indivíduo mais resiliente, explorador do mundo exterior, autoconfiante, complacente e prestativo em situações aflitivas, cooperativo e possuidor de ligações relacionais mais fortes. Em paralelo, têm-se os benefícios da prática da meditação da compaixão, que incluem o aumento da conexão social, a geração de diversas emoções positivas e a redução da evitação de pensamentos e/ou sentimentos difíceis. Vale ressaltar que lidar com as vivências subjetivamente classificadas como negativas impede seu acúmulo e, portanto, a multiplicação dessas sensações postas como indesejadas. Foram consultadas, nas plataformas Google Acadêmico, Portal do CAPES e Portal da Biblioteca PUC-Rio, em português e inglês, as expressões "meditação bondade amorosa e teoria do apego", "meditação da compaixão e teoria do apego", "compassion meditation and attachment theory" e "attachment security and meditation". Não foram identificadas pesquisas associando, especificamente, meditação da compaixão e teoria do apego. Contudo, a hipótese de a primeira influenciar a última não foi refutada, tendo indícios de confirmação ainda insuficientes. A meditação é cientificamente respaldada e estudada, porém possui pesquisas iniciadas recentemente, que não exploraram integralmente o assunto, sendo recomendáveis estudos experimentais e nos moldes científicos, para maior validação da prática e seus benefícios. Dentre eles, incluem-se as interseções e interferências entre meditação da compaixão e estilo de apego seguro.

Palavras-chave: Meditação. Compaixão. Autocompaixão. Teoria do apego.

\section{POLÊM!CA $\mid$ LABORE}

Polêmica - Revista Eletrônica da Uerj - Rua São Francisco Xavier, 524, $1^{\circ}$ andar bloco D, sl.1001 • Tels.: +55 21 2334-4088 / 4087 • http://www.e-publicacoes.uerj.br/index.php/polemica/index http://www.labore.uerj.br • laboreuerj@yahoo.com.br 


\section{ATTACHMENT THEORY AND (SELF) COMPASSION MEDITATION: HOW THE PRACTICE MAY AFFECT THE WAY THE INDIVIDUAL RELATES TO THE OTHER}

Abstract: This paper seeks, through a bibliographic review, to understand whether the practice of compassion meditation can be a useful tool to achieve a secure attachment style. The search for the latter is justified by corroborating with a more resilient individual, explorer of the outside world, self-confident, complacent and helpful in distressing situations, cooperative and possessing stronger relational connections. In parallel, there are the benefits of practicing compassion meditation, which include increasing social connection, generating several positive emotions and reducing avoidance of difficult thoughts and/or feelings. The Google Scholar platforms, CAPES Portal and PUC-Rio Library Portal were consulted, in Portuguese and English, the expressions "loving kindness meditation and attachment theory", "compassion meditation and attachment theory", "compassion meditation and attachment theory" and "attachment security and meditation". No research has been identified specifically associating compassion meditation and attachment theory. However, the hypothesis of the former influencing the latter has not been refuted, and there is still insufficient evidence of confirmation. The practice of meditation is scientifically supported and studied, but it has recently started research, which has not fully explored the subject, being interesting experimental and scientific studies to further validate the practice and its benefits. These studies include the intersections and interferences between compassionate meditation and secure attachment style.

Keywords: Meditation. Compassion. Self-compassion. Attachment theory.

\section{Introdução}

Deter um estilo de apego predominantemente seguro proporciona diversos benefícios ao indivíduo, cuja maneira de se relacionar demanda o desenvolvimento de determinadas habilidades. Assim, para enriquecimento das últimas, faz sentido pensar na prática da meditação da autocompaixão como ferramenta para tal, ideia essa que será investigada no presente artigo. Portanto, tem-se que, mediante uma revisão bibliográfica, as páginas a seguir se propõem a investigar se a prática da meditação da compaixão se faz útil como instrumento na busca de alcançar um estilo de apego seguro.

Primordialmente, faz sentido, portanto, definir apego, que seria um vínculo bidirecional, mutuamente regulado e assimétrico (BEEBE; LACHMANN, 1988), entre dois indivíduos, sendo um o membro vulnerável e o outro, aquele concebido como mais forte e mais sábio, o preferido (BOWLBY, 1977). Segundo Bowlby $(1982,1989)$, esse laço é um artifício primário para a manutenção/regulação da segurança da criança, que expressa uma ânsia de manter a intimidade ou a acessibilidade com a figura de ligação e, em retribuição, oferece profundo amor ao cuidador responsivo (BOWLBY, 1991).

Ocasionalmente, experimentos evidenciaram padrões de apego que foram, então, classificados de acordo com o comportamento exibido pela criança na "Situação Estranha" (AINSWORTH et al., 1978). Nela, é possível avaliar a díade cuidador-bebê, a partir da separação da dupla, seguida (minutos depois) da reunião. As classificações foram, portanto,

\section{POLÊM!CA $\mid$ LABORE}

Polêmica - Revista Eletrônica da Uerj - Rua São Francisco Xavier, 524, $1^{\circ}$ andar bloco D, sl.1001 • Tels.: +55 21 2334-4088 / 4087 • http://www.e-publicacoes.uerj.br/index.php/polemica/index http://www.labore.uerj.br • laboreuerj@yahoo.com.br 
construídas de acordo com as reações de ambos e resumem-se em: apego seguro; inseguroevitativo; inseguro-ambivalente; e, posteriormente, desorganizado (MAIN; HESSE, 1990).

Tais categorias de apego refletem diferentes tipos de competência afetiva, ou seja, diferenciadas estratégias relacionais para lidar com experiências afetivas intensas (FOSHA; SIEGEL; SOLOMON, 2009). Na primeira delas, observa-se o sentir e lidar enquanto se relaciona. Seria o apego seguro, no qual a criança é capaz de experienciar os sentimentos de separação e reunião, porém sem ser dominada por eles. As ligações ficam mais fortes e o indivíduo mais resiliente. Na situação estranha, a criança reclama e chora diante da separação, chegando a perder a vontade de brincar. Por outro lado, a reunião com a mãe é apaziguadora e a criança, agora calma, retoma sua brincadeira exploratória. Os pais encorajam a autonomia dos filhos, mas estão disponíveis quando procurados (BOWLBY, 1989). O filho busca a mãe tanto quando está contente quanto em situação de aflição. Nas palavras de Bowlby:

[...] uma base segura a partir da qual uma criança ou adolescente podem explorar o mundo exterior e a ele retornar certos de que serão bem-vindos, nutridos física e emocionalmente, confortados se houver um sofrimento e encorajados se estiverem amedrontados. Essencialmente, estar disponível, pronto para responder quando solicitado, para encorajar e, talvez, dar assistência, porém só intervindo quando for claramente necessário (BOWLBY, 1989, p. 25).

Na segunda, destacam-se sentir e não lidar. O indivíduo é inseguro, resistente e não consegue se afastar relacionalmente, sendo incapaz de modular seu próprio afeto. Ao ser separado da mãe, chora e continua a choramingar com o retorno da figura de apego, agarrandose a ela e sem retomar a brincadeira, ou seja, a criança sacrifica seu funcionamento independente e a exploração do meio em nome da relação. O problema, nesse caso, é a confiabilidade imprevisível da figura de ligação, deflagrando uma mistura de ansiedade excessiva com o afeto. Trata-se da mesclagem de lamento, ansiedade e exclusão defensiva da raiva que poderia ameaçar o relacionamento. Assim, as defesas regressivas se manifestam, utilizando certos afetos para se proteger de outros mais repletos de ansiedade. Trata-se, então, o apego resistente, ao qual Bowlby (1989) se refere como resistente e ansioso, sendo a disponibilidade do cuidador incerta, levando à ansiedade de separação e à busca por não se distanciar da figura de apego. Nesse modelo, os pais se mostram disponíveis em algumas situações e em outras não, sendo usadas ameaças de abandono como meio de controle.

Quanto à terceira, lidar e não sentir, a criança insegura e esquiva sacrifica sua vida afetiva. Ela não interrompe a brincadeira, não demonstra aflição pela separação ou alegria pela

\section{POLÊM!CA $\mid$ LABORE}

Polêmica - Revista Eletrônica da Uerj - Rua São Francisco Xavier, 524, $1^{\circ}$ andar bloco D, sl.1001 • Tels.: +55 21 2334-4088 / 4087 • http://www.e-publicacoes.uerj.br/index.php/polemica/index http://www.labore.uerj.br • laboreuerj@yahoo.com.br 
reunião, agindo com indiferença à presença ou ausência da figura de ligação (FOSHA; SIEGEL; SOLOMON, 2009). Todavia, fisiologicamente, está igualmente ameaçada pelas vicissitudes do apego de seus correspondentes mais expressivos (CASSIDY, 1994), fazendo uso da estratégia defensiva de supressão emocional para manter o relacionamento. Consequentemente, a criança minimiza a importância da relação para suprimir sua carga emocional, o que pode torná-la predisposta a problemas futuros (FOSHA; SIEGEL; SOLOMON, 2009). Quanto ao engajamento relacional, é mínimo, uma vez que sentir e se relacionar são aspectos intimamente ligados. Essa seria a ligação esquiva, que resulta em isolamento, alienação, empobrecimento emocional futuros e uma frágil consolidação do self. Assim, tem-se o apego ansioso com evitação descrito por Bowlby (1989), no qual o indivíduo acredita que será rejeitado caso peça ajuda e só procura a mãe quando está contente, pois a criança pode buscar uma vida sem amor e sem amparo, rumo à autossuficiência emocional.

Por último, nem sentir, nem lidar. Trata-se da ligação desorganizada/confusa, na qual a figura de apego desliga-se apenas emocionalmente, de forma momentânea, e o indivíduo é tomado pelo medo e confusão que são transmitidos pelos pais (MAIN; HESSE, 1990). Segundo Fosha, Siegel e Solomon (2009), isso produz ansiedade e afeto intensos, resultando numa divisão na consciência e numa consequente desorganização. A ligação é ameaçada, portanto, o indivíduo passa a apresentar uma vulnerabilidade à desintegração, intensificando o perigo experienciado, fazendo-o sentir-se apavorantemente sozinho. Os afetos rompem a organização da cognição, do comportamento e fragmentam a integridade do self (FOSHA; SIEGEL; SOLOMON, 2009), visto que o relacionamento fracassa em fornecer o mais rudimentar auxílio para abrandar o medo (MAIN, 1995), que pode ser potencializado (FOSHA; SIEGEL; SOLOMON, 2009) em virtude da figura de ligação ora ser vista como assustadora, ora como assustada (MAIN, 1995). Há, por conseguinte, uma abertura à dissociação e à cisão da personalidade, visando uma desintegração psíquica ainda mais disseminada diante do perigo.

Após a exposição dos estilos de apego acima, ficam evidentes os benefícios de uma relação segura, na qual a figura de ligação acalma o medo do mais frágil, dado que esse sentimento de apavoramento ativa o mecanismo de apego, restringindo a exploração (FOSHA; SIEGEL; SOLOMON, 2009). Outras situações que também estimulam essa ferramenta são, por exemplo, em caso de doença, dor ou fadiga (BOWLBY, 1977, 1989).

\section{POLÊM!CA $\mid$ LABORE}

Polêmica - Revista Eletrônica da Uerj - Rua São Francisco Xavier, 524, $1^{\circ}$ andar bloco D, sl.1001 • Tels.: +55 21 2334-4088 / 4087 • http://www.e-publicacoes.uerj.br/index.php/polemica/index http://www.labore.uerj.br • laboreuerj@yahoo.com.br 
A sensação de segurança possibilita a manifestação de motivações primárias, como explorar, atender a curiosidade e ambicionar novas experiências (LACHMANN; BEEBE, 1992), ou seja, quando não oprimida pelo medo, a criança investiga o seu mundo e adquire conhecimentos ao dominar novas situações, ampliando seus recursos de adaptação (FOSHA; SIEGEL; SOLOMON, 2009). Assim, o indivíduo acaba por experienciar sentimentos como eficiência, competência (WHITE, 1960), euforia e orgulho (EMDE, 1988; KISSEN, 1995), indicadores afetivos do sistema comportamental exploratório (FOSHA; SIEGEL; SOLOMON, 2009).

Salienta-se ser por meio da ligação afetiva que a criança se beneficia não só de seus próprios recursos, mas também daqueles de sua figura de ligação, desfazendo a solidão diante de perigos (FOSHA; SIEGEL; SOLOMON, 2009). Tal ideia também justifica o principal perigo no mundo emocional, nessa fase da vida, que é ter uma figura de ligação inacessível ou desinteressada (BOWLBY, 1989).

Uma vez esclarecida, de acordo com a teoria do apego, quais as necessidades devem ser supridas para o desenvolvimento de um indivíduo saudável, as linhas que se seguem procuram esclarecer como os cuidadores podem fazê-lo. Bowlby (1989) propõe que a atitude para acalmar a criança depende da intensidade do fator que deu origem ao comportamento, sendo, por vezes, suficiente ouvir a mãe. Por outro lado, quando o indivíduo está extremamente ansioso, um contato físico mais intenso, como um abraço, é mais eficaz. Se tudo está bem, tem-se satisfação e senso de segurança por parte da criança. Se há ruptura, tem-se dor e depressão. Se há ameaça na relação, tem-se ciúme, ansiedade e raiva. Todas são emoções muito válidas, pois buscam a manutenção daquela relação tendo em vista que todos os esforços do mais vulnerável são voltados para tal. A raiva, por exemplo, quando adequada, serve para deter um comportamento perigoso, livrar alguém de um rival ou coagir um parceiro, em suma, proteger a relação.

Observa-se, portanto, que diante das adversidades, constroem-se as defesas - uma "tentativa de neutralizar a pungente ansiedade gerada pela falha da figura de ligação em ser responsiva e prover maternagem” (FOSHA; SIEGEL; SOLOMON, 2009, p. 39). Afinal, uma resposta não minimamente satisfatória do cuidador se integra no modelo funcional interno e reflete nos padrões de ligação do indivíduo (BOWLBY, 1980). As técnicas defensivas se dão como respostas de enfrentamento organizadoras que procuram reduzir a aflição e proteger o

\section{POLÊM!CA $\mid$ LABORE}

Polêmica - Revista Eletrônica da Uerj - Rua São Francisco Xavier, 524, $1^{\circ}$ andar bloco D, sl.1001 • Tels.: +55 21 2334-4088 / 4087 • http://www.e-publicacoes.uerj.br/index.php/polemica/index http://www.labore.uerj.br • laboreuerj@yahoo.com.br 
indivíduo, todavia, possuem consequências adversas; uma delas, o desenvolvimento de uma patologia (FOSHA; SIEGEL; SOLOMON, 2009).

Ao dar seguimento às consequências do não suprir essas necessidades da criança, evidencia-se que, com o objetivo de se relacionar da melhor maneira possível, ela exclui de sua experiência os aspectos que a figura de ligação possa não tolerar, tentando impedir o afastamento, ou seja, ocorre o sacrifício da plenitude de realidade da criança, seus relacionamentos e sua vida afetiva interna (FOSHA; SIEGEL; SOLOMON, 2009). O resultado é uma sensação secundária de segurança (MAIN, 1995), a força que mantém esses padrões. Dáse início, então, a um isomorfismo (COSTELLO, 2000 apud FOSHA; SIEGEL; SOLOMON, 2009) entre o que é comunicado à mãe e o que pode ser comunicado ao self (BOWLBY, 1991) e, por consequência, o que não for levado à mãe passa a não ser refletido e experienciado, mesmo na privacidade de vida interior da criança.

Toda essa dinâmica tem uma função biológica, segundo Bowlby (1989), de proteção, em especial, frente a possíveis predadores. A explicação consiste em o homem e outros animais responderem a um sinal de risco com o medo. Ele permite respostas a movimentos rápidos ou modificações marcantes, facilitando a compreensão do porquê a ameaça de separação é aterrorizante, a razão das ameaças de abandono criarem ansiedade e fazerem surgir raiva. A última se faz útil para que a pessoa possa dissuadir a figura de apego de continuar a ameaça. Em contraponto, relações seguras proporcionam o desenvolvimento da competência afetiva ser capaz de sentir e processar emoções para um funcionamento ótimo, sem comprometer a integridade do self e o relacionamento com o provedor de segurança (FOSHA; SIEGEL; SOLOMON, 2009).

Outro apontamento de suma importância é que a função de maternagem não está limitada aos adultos formalmente designados como figuras de ligação (FOSHA; SIEGEL; SOLOMON, 2009). Afinal, as experiências de relacionamento se dão com aquele que presta cuidados ao bebê e têm início no primeiro ano da vida, com repetição constante durante a infância e a adolescência (BOWLBY, 1980). Tal reforço corrobora para que o relacionamento de apego seja representado e internalizado, ou seja, diferentes indivíduos irão interagir com esse sujeito, influenciando seu padrão de conexão. Por sua vez, essas representações internas fornecerão ao indivíduo base para compreender a forma de tratar a experiência afetiva relacional, o que moldará o funcionamento e a personalidade, além de orientar a maternagem

\section{POLÊM!CA $\mid$ LABORE}

Polêmica - Revista Eletrônica da Uerj - Rua São Francisco Xavier, 524, $1^{\circ}$ andar bloco D, sl.1001 • Tels.: +55 21 2334-4088 / 4087 • http://www.e-publicacoes.uerj.br/index.php/polemica/index http://www.labore.uerj.br • laboreuerj@yahoo.com.br 
do indivíduo, caso venha a ter crianças. Inclusive, violência é uma das maiores responsáveis por certa quantidade de síndromes psiquiátricas confusas e dolorosas e, nas famílias, tende a se perpetuar de uma geração a outra (BOWLBY, 1989). Isto é, o cuidador não responsivo ou confiável cria seres cujo self não se considera digno de ser protegido e respondido (FOSHA; SIEGEL; SOLOMON, 2009), causando consequências diversas e que se perpetuam para a vida e, possivelmente, para as futuras gerações.

Esse cenário é explicado por uma tendência de círculo vicioso (BOWLBY, 1989), em que uma criança ansiosa e ambivalente tende a ser resmungona e agarrada aos pais; a ansiosa e evitativa se mantêm distante e tende a implicar com as outras crianças. O comportamento delas tende a favorecer uma resposta desfavorável da parte dos pais, criando um ciclo. Em contrapartida, filhos seguros e felizes tendem a ser mais cooperativos no cuidado e menos exigentes, recebem respostas favoráveis e, igualmente, seguem seu ciclo.

Por fim, para o encerramento desta primeira parte da introdução, faz-se crucial destacar alguns pontos. O primeiro: o membro mais vulnerável reconhece em si apenas o que o cuidador reconheceu nele. O segundo: "se um dos pais passa a tratar a criança de forma diferente, o modelo também se modifica" (BOWLBY, 1989, p. 124). O terceiro: conforme a criança cresce, o modelo se torna cada vez mais uma propriedade da própria, o que quer dizer que ela tende a impô-lo às novas relações. Ao levarem-se em consideração essas três informações, faz sentido pensarmos o que poderia ajudar o indivíduo a modificar o tipo de apego predominante até então e que ferramentas poderiam auxiliá-lo nesse processo. Portanto, nas páginas subsequentes, pretende-se entender o que é meditação e se a prática pode corroborar com essas mudanças ao influenciar positivamente a reestruturação de relações de apego.

\section{Meditação}

\section{O que é meditação?}

Na busca por definir meditação, podemos analisar Slagter et al. (2007), que apontam o ato de meditar como um treinamento da mente que tem a capacidade de fornecer uma maior integração entre mundo exterior, corpo e mente. Pode também ser vista como uma transferência da consciência do mundo externo para o interno (NARANJO, 2005). Além disso, seria uma

\section{POLÊM!CA $\mid$ LABORE}

Polêmica - Revista Eletrônica da Uerj - Rua São Francisco Xavier, 524, $1^{\circ}$ andar bloco D, sl.1001 • Tels.: +55 21 2334-4088 / 4087 • http://www.e-publicacoes.uerj.br/index.php/polemica/index http://www.labore.uerj.br • laboreuerj@yahoo.com.br 
resposta de relaxamento (CAMPAGNE, 2004), uma técnica comportamental (CARDOSO, 2005) ou uma técnica mente-corpo (KABAT-ZINN, 2003).

Destaca-se que esses conceitos sofrem influência do ponto de vista cultural. Evidência é que, no Oriente, meditar é realizar uma busca espiritual, enquanto no Ocidente - tomando como parâmetro as pesquisas científicas - são práticas que têm o intuito de autorregular o corpo e a mente (MENEZES; DELL'AGLIO, 2009). Todavia, nas pesquisas anteriormente mencionadas, mostrou-se notório que, apesar das variadas definições, o que há em comum no meditar é a busca por controlar a atenção (GOLEMAN, 1988). Da mesma forma, as pesquisas analisadas por Menezes e Dell'Aglio (2009), sugerem a existência de uma uniformidade, em algum grau, no que diz respeito aos efeitos das práticas meditativas.

Por sua vez, Cardoso et al. (2004) propõem a meditação como uma técnica específica e nitidamente definida que leva a um nível de relaxamento muscular e mental em meio à realização do processo. $\mathrm{O}$ estado alcançado seria exclusivamente autoinduzido, valendo-se de um foco-âncora. De forma complementar, Shapiro (1981) coloca a meditação como uma prática que inclui um grupo de técnicas que procuram treinar o focalizar a atenção. Assim sendo, meditar pode ser considerado um processo autorregulatório da atenção, tendo em vista que, por meio da prática, é desenvolvido o controle dos processos atencionais (DAVIDSON; GOLEMAN; SCHWARTZ, 1976).

O fato é que existem diferentes tipos de meditação e, portanto, diferentes definições. Bishop et al. (2004), por exemplo, propuseram uma definição operacional para a meditação do tipo mindfulness, que abrange dois aspectos fundamentais. São eles: a atitude de abertura, aceitando o momento presente, e a autorregulação da atenção. Salvo as particularidades de cada método, outras variáveis, incluindo inclinações genéticas, aspectos da personalidade, vivências únicas, expectativas, motivações e valores também podem influenciar de alguma forma o tipo e a qualidade da resposta da prática meditativa (DAVIDSON; GOLEMAN, 1977). Por fim, dentre a enorme variedade de técnicas, encontra-se o programa TCC (Treinamento de Cultivo de Compaixão), que busca investigar cientificamente o comportamento altruísta e suas motivações, sobretudo, a compaixão, que será mais abordada ao longo do artigo (JINPA, 2016).

\section{POLÊM!CA $\mid$ LABORE}

Polêmica - Revista Eletrônica da Uerj - Rua São Francisco Xavier, 524, $1^{\circ}$ andar bloco D, sl.1001 • Tels.: +55 21 2334-4088 / 4087 • http://www.e-publicacoes.uerj.br/index.php/polemica/index http://www.labore.uerj.br • laboreuerj@yahoo.com.br 


\section{Compaixão e autocompaixão}

Frente ao intuito de verificar se a prática da meditação voltada para a compaixão (incluindo a autocompaixão) pode corroborar em uma mudança nas relações de apego do indivíduo, é evidente a necessidade de conceituar-se compaixão em si. Segundo Jinpa (2016), compaixão é colocar o outro como prioridade. Mais especificamente, trata-se de se preocupar frente ao sofrimento de outrem e desejar que tal sentimento chegue ao fim. Em outros termos, compaixão consiste na capacidade humana natural de entender o sentimento do outro e partilhar sua própria experiência, além de envolver uma ação instintiva.

Ainda de acordo com o autor, a compaixão seria o elo entre empatia e atos de bondade, generosidade e outras formas de expressão do que ele chama de "nossas tendências altruístas". Em sua perspectiva, o homem é um ser social, com instintos de compaixão e bondade, além de interdependente (seu bem-estar tem ligação com o dos seus semelhantes), características essas que afetam sua forma de ver e estar no mundo. Tal pensamento está em concordância com os de outros estudiosos, dentre eles, podemos citar Bowlby: "os bebês humanos, como os bebês de outras espécies, são pré-programados para se desenvolverem de uma forma socialmente cooperativa; se isso ocorre ou não depende do modo como são tratados" (BOWLBY, 1989, p. 24). Com ideais semelhantes, o cientista Paul Ekman (2014) defende que devemos alcançar a "compaixão global".

Outras contribuições foram trazidas por Goetz, Keltner e Simon-Thomas (2010), ao revisarem estudos científicos com essa temática. Os autores concluíram que a compaixão vai além da angústia empática e trata-se de mais que um subtipo ou mistura de tristeza e amor, pois advém de processos de avaliação diferentes e exibem comportamentos distintos, resultando em experiências diferenciadas. Eles verificaram, também, que a compaixão tem um valor evolutivamente funcional no cuidado de uma prole vulnerável; que os mais compassivos foram escolhidos de forma prioritária na seleção de parceiros; e que a compaixão foi tratada como traço desejável nas relações de cooperação entre pessoas sem parentesco.

Ainda dentro dessa definição, faz-se interessante buscar o que a psicologia ocidental afirma: a compaixão seria uma combinação entre razões, emoções, pensamentos e comportamentos que possibilitam estar disponível para o próprio sofrimento e o dos outros para que, assim, seja possível percebê-lo de maneira não avaliativa. Pode-se, então, efetivamente agir em nome do seu alívio (GILBERT, 2005).

\section{POLÊM!CA $\mid$ LABORE}

Polêmica - Revista Eletrônica da Uerj - Rua São Francisco Xavier, 524, $1^{\circ}$ andar bloco D, sl.1001 • Tels.: +55 21 2334-4088 / 4087 • http://www.e-publicacoes.uerj.br/index.php/polemica/index http://www.labore.uerj.br • laboreuerj@yahoo.com.br 
Na prática, segundo Jinpa (2016), nunca se livra dos ditames da compaixão, afinal, o ser humano nasce dependente de cuidado e segue influenciado pela afeição dos outros - que determinam, por exemplo, felicidade ou tristeza. Além disso, o autor aponta a necessidade de propósito e a relaciona com conectar com os outros, fazendo uma diferença real e ainda coloca que, na tradição tibetana, a compaixão seria "o mais alto ideal espiritual e a mais alta expressão de nossa humanidade" (p. 53).

No que diz respeito aos benefícios desse sentimento, Jinpa (2016) coloca o aumento da paciência, compreensão e bondade do indivíduo que a sente, tornando-o disposto a se expor à realidade do sofrimento e à procura de seu alívio. Outros autores, como Brandon et al. (2010), evidenciaram que há benefícios em receber a bondade alheia, diferenciados a depender do nível de compaixão de cada um. Em sua pesquisa, concluíram que indivíduos mais compassivos podem encontrar mais benefícios no incentivo de outrem, em particular, sob estresse agudo. O estudo contou com 59 mulheres divididas em dois grupos. Todas preencheram uma escala de compaixão, todavia, um dos grupos recebia incentivos positivos para realizar as tarefas propostas e o outro não. Eletrodos foram posicionados na cabeça das participantes, objetos esses que mediam suas ondas cerebrais e algumas funções corporais. Os resultados foram que aqueles que receberam sinais incentivadores e tiveram mais alta pontuação no nível de compaixão expressaram mais gosto pelos pesquisadores e apresentaram também mais baixa pressão sanguínea e presença de cortisol e maior variabilidade dos batimentos cardíacos. Ou seja, indicadores associados à saúde física e ao bem-estar social foram destacados e mostraram um melhor desempenho. Pelo contrário, aqueles com baixo nível de compaixão que receberam estímulos semelhantes e os participantes com alto nível de compaixão que não foram encorajados não tiveram essas alterações, esses efeitos.

Para dar prosseguimento aos benefícios, destaca-se que a realização de gestos bondosos por compaixão traz consigo o sentir-se bem, já que é afirmado o traço fundamental da condição humana de necessidade e gratidão pelos vínculos com outros seres humanos (JINPA, 2016). Além disso, possibilita ver além dos próprios interesses e a sensação de ser parte de algo maior - ideias reafirmadas por Layous et al. (2012). Em um de seus estudos, crianças foram instruídas a realizar três atos de bondade ou visitar três lugares, relatando o que faziam a cada semana, em sala de aula. Antes e depois da intervenção de quatro semanas, os alunos preencheram escalas de satisfação com a vida, felicidade e afeto positivo, além de circularem, na lista de colegas,

\section{POLÊM!CA $\mid$ LABORE}

Polêmica - Revista Eletrônica da Uerj - Rua São Francisco Xavier, 524, $1^{\circ}$ andar bloco D, sl.1001 • Tels.: +55 21 2334-4088 / 4087 • http://www.e-publicacoes.uerj.br/index.php/polemica/index http://www.labore.uerj.br • laboreuerj@yahoo.com.br 
todos os nomes com quem gostariam de passar tempo. Os resultados demonstraram que fazer o bem para os outros traz benefícios para o sujeito da ação, que seriam melhor bem-estar (aumento em seu nível de felicidade) e maior aceitação entre seus pares. Assim como "ser feliz", ser querido pelos colegas tem ramificações para o indivíduo e para comunidade em geral, o que pode ser exemplificado pelas relações entre pré-adolescentes, na qual os populares exibem comportamentos mais inclusivos e menos bullying na adolescência. Outro benefício de se encorajar atividades pró-sociais é ter salas de aula sem favoritos e sem crianças marginalizadas, o que, por sua vez, melhora a saúde mental média dos indivíduos em relação às salas estratificadas.

Temos que a compaixão contribui para relacionamentos melhores, além de se opor à solidão, estimular a bondade ajuda, mais que a manter os vínculos queridos intactos, a evitar rompimentos que as desavenças e o distanciamento emocional podem causar. Outro efeito benéfico da compaixão é sobre o estresse, em razão de uma postura compreensiva e tolerante tender a acompanhá-la. Por conseguinte, fica-se menos incomodado e ofendido pelos outros, quando sente-se compaixão em relação a eles. Ademais, compaixão e autocompaixão trazem uma maior gentileza e paciência com as próprias falhas, diminuindo a procura por esconder supostas imperfeições estruturadas, por sua vez, pelo autojulgamento severo - despertador da vergonha. Ou seja, ser mais compassivo acaba por diminuir o estresse: "Com a sinceridade, a aceitação e a transparência que vêm com a autocompaixão, não temos mais nada a esconder. E, com nada a esconder, temos menos coisas de que ter medo" (JINPA, 2016, p. 23).

Quanto às vantagens da autocompaixão, são destacáveis estar menos atento a expectativas sociais, mais voltado ao próprio bem-estar e verdadeiras necessidades, o que implica no estabelecimento de metas mais significativas pessoalmente e mais viáveis. Ademais, há um menor risco de permanecer em constante autocrítica e derrotismo, pois a compaixão influencia o indivíduo a aceitar que decepções e fracassos são inerentes ao humano, que, então, abre mão da busca de nunca falhar. Consequentemente, frente a um menor medo de erros, há mais disposição a olhá-los, aprender e seguir adiante. Outro ponto é que a autocompaixão torna mais viável a extensão da compaixão e bondade aos outros, evita o esgotamento, o pessimismo, o desespero em meio a adversidades e, ao invés de se questionar a razão dos acontecimentos, percebe-se não estar sozinho. Ela permite uma maior resiliência e compreensão, aceitação e

\section{POLÊM!CA $\mid$ LABORE}

Polêmica - Revista Eletrônica da Uerj - Rua São Francisco Xavier, 524, $1^{\circ}$ andar bloco D, sl.1001 • Tels.: +55 21 2334-4088 / 4087 • http://www.e-publicacoes.uerj.br/index.php/polemica/index http://www.labore.uerj.br • laboreuerj@yahoo.com.br 
senso de proporção. Ou seja, em suma, há um estabelecimento de metas realistas, o renovar forças, menor sentimento de estar só e aprender por meio da experiência (JINPA, 2016).

\section{Meditação para compaixão e autocompaixão}

Posto o que é compaixão, autocompaixão e os benefícios de ambos, faz-se coerente entrar na meditação voltada para tal. De acordo com os estudos de Amato et al. (2012), meditação de compaixão, Mettã (assim conhecida pelos budistas) e meditação da bondade amorosa (Loving-Kindness) são diferentes denominações para uma mesma prática. São métodos em que o praticante deseja liberdade frente ao sentimento de sofrimento (JINPA, 2016) e corroboram com o cultivo e desenvolvimento de amor incondicional, empatia, bondade e compaixão, tanto pelo outro, quanto por si próprio e por todas as formas de vida (JINPA, 2016; AMATO et al., 2012). Jinpa (2016), então, traz o treinamento para a meditação da compaixão que envolve o cultivar de três habilidades, sendo elas: desenvolver a concentração por meio da atenção focada, aquietar a mente e fortalecer a consciência.

Dentro da primeira, inclui-se o estabelecimento da intenção (uma autochecagem para interligar-se às próprias aspirações que, por sua vez, moldarão intenções e motivações), combinado com a dedicação (revisitar seu dia, verificando se condiz com sua intenção e os bons sentimentos experienciados). Vale esclarecer que a motivação corresponde à razão (à vontade) e a intenção corresponde a uma escolha que "pode influenciar nosso humor, nossos pensamentos e sentimentos - estabelecendo uma intenção pela manhã, criamos o tom do dia" (JINPA, 2016, p. 54), ou seja, é possível optar por ser bondoso consigo (autocompaixão).

O passo seguinte é usar da prática contemplativa como um meio de "aquietar a mente a partir de dentro - não fugindo dela, mas nos aproximando; não nos distraindo, mas colocandoa para funcionar" (JINPA, 2016, p. 64). Tal prática integraria habilidade de focalizar e de se abrir (SHAPIRO, 1981; SHAPIRO; SCHWARTZ; SANTERRE, 2005; JINPA, 2016), afinal, procura desenvolver a concentração, ao empregar atenção em um objeto de forma consciente e manter esse foco por algum tempo (JINPA, 2016). Primeiro, em razão de o envolvimento ativo ajudar na organização mental, para alcançar esses objetivos, é conveniente optar por um exercício de atenção focada por meio da respiração consciente, cuja atenção é mantida nos movimentos respiratórios. O segundo passo é compor "um conjunto de pensamentos para

\section{POLÊM!CA $\mid$ LABORE}

Polêmica - Revista Eletrônica da Uerj - Rua São Francisco Xavier, 524, $1^{\circ}$ andar bloco D, sl.1001 • Tels.: +55 21 2334-4088 / 4087 • http://www.e-publicacoes.uerj.br/index.php/polemica/index http://www.labore.uerj.br • laboreuerj@yahoo.com.br 
formar um pano de fundo a partir do qual nossos pensamentos e emoções subsequentes possam emergir" (JINPA, 2016, p. 53).

Em terceiro lugar, está a etapa da consciência metacognitiva ou metaconsciência, que seria a capacidade de atingir um grau maior de consciência em relação, por exemplo, a pensamentos, sentimentos, ações e arredores. Ela consiste em trazer consciência à dinâmica dos próprios pensamentos, emoções e comportamentos, distanciando-se e observando as passagens mentais no papel de espectadores objetivos. O foco da prática moderna da atenção plena está na capacidade de presença, enquanto observa-se (sem julgamento) corpo, sentimentos e seus conteúdos (JINPA, 2016).

Esses exercícios contribuem para acalmar a mente, relaxá-la, e, por conseguinte, faz-se viável estar genuinamente presente e mais disponível para cuidar de todos. É uma busca por conter a divagação, dificultadora da atenção ao que se deseja de fato, e liberar recursos mentais que, de outra forma, se dispersariam. Uma melhora na atenção gera uma maior consciência e compreensão da vivência de todos os indivíduos, gerando empatia. Do contrário, para Jinpa (2016), negar ou resistir ao sofrimento e outros sentimentos percebidos como negativos aumenta o grau dessas emoções e inibe a conexão com o sofrer alheio. Enquanto isso, a metaconsciência permite lidar sem visitar a sensação de ameaça, afinal, encontra-se um lugar para o sofrimento, sem surpresa ou confusão. Dessa maneira, o instinto compassivo não é contido pelo medo e pode se expressar.

Vale destacar que Jinpa (2016) tem suas raízes nas práticas tradicionais budistas, cujas visões sistemáticas costumam ter início no próprio indivíduo, suas aspirações à felicidade e desejo de não sofrer. A partir disso, busca eleger-se uma pessoa amada o mais palpável possível e focar a atenção em suas dores, desejando-lhe amor-bondade (alegria, felicidade e paz) e compaixão (não sofrer). Em tese, um alvo simples para desejar o bem é alguém cujo sofrimento é sabido e a relação interpessoal é descomplicada. Então, em círculos de atenção sempre em expansão, repetem-se os mesmos desejos a alguém subjetivamente indiferente para si e, em seguida, para uma pessoa "complicada". Finalmente, de forma ampla, estima-se alegria, felicidade e paz para todos os seres. Na prática, faz-se uma respiração profunda, seguida de uma contagem da respiração ou um exercício de consciência da respiração e, então, mentaliza-se:

Pense numa época em que a pessoa que você tem em mente estava passando por uma experiência difícil. [...] Tente imaginar como ela se sente. [...] Se não surgirem sentimentos ou sensações específicas, fique com o pensamento. Sejam quais forem os

\section{POLÊM!CA $\mid$ LABORE}

Polêmica - Revista Eletrônica da Uerj - Rua São Francisco Xavier, 524, $1^{\circ}$ andar bloco D, sl.1001 • Tels.: +55 21 2334-4088 / 4087 • http://www.e-publicacoes.uerj.br/index.php/polemica/index http://www.labore.uerj.br • laboreuerj@yahoo.com.br 
sentimentos e pensamentos que surgirem, fique com eles. Então, imaginando o sofrimento dessa pessoa, ofereça silenciosamente as seguintes frases: "Que você seja livre do sofrimento. Que você seja livre do medo e da ansiedade. Que você encontre segurança e paz”. (JINPA, 2016, p. 79-80).

Por fim, dentre os benefícios dessa modalidade de meditação incluem-se lidar com os sintomas negativos da esquizofrenia, distresse, ansiedade, dores persistentes, depressão, sequelas emocionais da fibromialgia e da síndrome da fadiga crônica (AMATO et al., 2012). Mais que isso, esse tipo de meditação propicia o aumento da conexão social e gera diversas emoções positivas (tais como bem-estar, esperança e empatia). Ou seja, tal prática é uma boa parceira no tratamento de diversas doenças e um recurso auxiliar no processo psicoterapêutico. Além disso, o treinamento de autocompaixão demonstrou reduzir a evitação de pensamentos e sentimentos difíceis após um evento estressante (NEFF; GERMER, 2013). Vale igualmente ressaltar que, segundo Amato et al. (2012), os benefícios alcançados pela prática se mantêm mesmo depois de ter sido finalizada há algum tempo e, no caso de dar-se continuidade, há maiores benefícios.

Diante do conhecimento exposto imediatamente acima e destacando-se a meditação como possível colaboradora para conexão social e emoções positivas, não é difícil pensar sua influência em diferentes aspectos da vida, por exemplo, no estilo de relacionamento em si e, portanto, no padrão de apego constituído na infância. Com isso, realizou-se uma revisão bibliográfica de estudos que relacionam meditação da autocompaixão e teoria do apego.

\section{Teoria do apego e meditação da compaixão}

Ao consultarem-se as plataformas Google Acadêmico, Portal do CAPES e Portal da Biblioteca PUC-Rio, não foram achadas pesquisas associando especificamente meditação da compaixão e teoria do apego, seja em português ou inglês, tendo sido buscadas as expressões "meditação bondade amorosa e teoria do apego", "meditação da compaixão e teoria do apego", "compassion meditation and attachment theory" e "attachment security and meditation". Todavia, foram encontrados dados que relacionam compaixão e estilo de apego, meditação e compaixão, dentre outras informações válidas para fazer essa correlação, como exposto nas páginas subsequentes.

Kirby (2017), por exemplo, encontrou oito intervenções baseadas na compaixão (incluindo Terapia focada na compaixão, Autocompaixão consciente, Treinamento para cultivar a compaixão e Treinamento da compaixão com base cognitiva), intervenções essas que

\section{POLÊM!CA $\mid$ LABORE}

Polêmica - Revista Eletrônica da Uerj - Rua São Francisco Xavier, 524, $1^{\circ}$ andar bloco D, sl.1001 • Tels.: +55 21 2334-4088 / 4087 • http://www.e-publicacoes.uerj.br/index.php/polemica/index http://www.labore.uerj.br • laboreuerj@yahoo.com.br 
apresentaram efeito moderado na melhora de satisfação com a vida e no lidar com o sofrimento. Uma delas, apresentada por Navarro-Gil et al. (2020), é o protocolo denominado ABCT (Attachment-Based Compassion Therapy), cuja base é a teoria do apego, que inclui práticas que objetivam conscientizar e apontar possíveis aspectos não adaptativos dos estilos de apego estabelecidos com os primeiros cuidadores. O ABCT é composto por oito sessões de duas horas e meia, nas quais são aplicadas técnicas de atenção plena e práticas de compaixão. As práticas relacionadas ao segundo seriam receber compaixão e oferecê-la a si e aos outros - prática trabalhada na meditação da compaixão/Metta (JINPA, 2016). A ideia é ajudar na identificação do próprio estilo de apego predominante e percepção de sua influência nos relacionamentos interpessoais atuais, consequentemente, impactando nas relações e no bem-estar do indivíduo praticante, sendo uma forma de compaixão e autocompaixão (NAVARRO-GIL et al., 2020).

Em tal estudo, Navarro-Gil et al. (2020) realizaram um ensaio clínico não randomizado (dificultando o descarte de possíveis vieses) com grupos de intervenção e controle (lista de espera), tendo aplicado avaliações antes, logo após e seis 6 meses pós-intervenção. Os participantes eram adultos saudáveis, que se autorrelataram sem transtornos psicológicos e fora de tratamento psiquiátrico. As escalas preenchidas foram: Self-Compassion Scale (SCS), que mede benevolência, autojulgamento, humanidade comum, isolamento, atenção plena e superidentificação; Five Facets of Mindfulness Questionnaire (FFMQ), que mede a disposição pessoal de atenção no dia a dia (observação, capacidade de descrever, agir com consciência, não julgamento da experiência interior e não reatividade à experiência interior); Acceptance and Action Questionnaire (AAQ-II), que mede a evitação de experimentar emoções indesejáveis, pensamentos e eventos angustiantes; General Health Questionnaire (GHQ-28), que mede as subescalas de sintomas somáticos, ansiedade/insônia, disfunção social e depressão grave; e Relationship Questionnaire, que avalia o estilo de apego.

O ABCT foi capaz de reduzir significativamente os níveis de ansiedade e evitação e o estilo de apego seguro aumentou consideravelmente (NAVARRO-GIL et al., 2020). Mais especificamente, por meio dos parâmetros de escalas escolhidas pelos autores, concluiu-se que ABCT é eficaz para: melhorar a autocompaixão em todos os itens da escala SCS, exceto o isolamento; melhorar todas as escalas do FFMQ, exceto na capacidade de descrever com palavras, eventos e respostas pessoais; diminuir a evitação experiencial avaliada por meio do AAQ-II; diminuir o distúrbio psicológico medido pelo GHQ-28.

\section{POLÊM!CA $\mid$ LABORE}

Polêmica - Revista Eletrônica da Uerj - Rua São Francisco Xavier, 524, $1^{\circ}$ andar bloco D, sl.1001 • Tels.: +55 21 2334-4088 / 4087 • http://www.e-publicacoes.uerj.br/index.php/polemica/index http://www.labore.uerj.br • laboreuerj@yahoo.com.br 
Em suma, Navarro-Gil et al. (2020) concluíram que o ABCT pode ser uma intervenção eficaz para melhorar a autocompaixão e o estilo de apego em adultos saudáveis, ao perceberem seus efeitos na autocompaixão, atenção plena, evitação experiencial (níveis diminuídos), sofrimento psicológico, ansiedade (níveis diminuídos) e evitação relacionada ao estilo de apego. Vale destacar que os resultados frente à ansiedade e evitação relacionados ao apego se mantiveram, além do apego seguro ter sofrido significativa mudança, salvo o apego desorganizado (que não apresentou melhorias), no pós-teste e no acompanhamento. O estudo foi controlado, teve uma amostra suficientemente grande, seguiu o protocolo manualizado e a avaliação da adesão ao protocolo não foi feita pelo mesmo terapeuta.

De forma complementar, outros estudos relacionaram autocompaixão e apego, tal qual o de Krasuska et al. (2017 apud NAVARRO-GIL et al., 2020), que colocam a compaixão como possível ferramenta terapêutica para pacientes com apego inseguro. Isso faz sentido, em razão de descobertas como as de Gilbert et al. (2014 apud NAVARRO-GIL et al., 2020), que encontraram uma correlação entre o medo de experienciar as sensações trazidas ao acessar o sentimento compaixão e alexitimia, transtorno depressivo, ansiedade e estresse, sendo a autocompaixão crucial para a compreensão das associações entre a ansiedade do apego e a apreciação do corpo (RAQUE-BOGDAN et al., 2016 apud NAVARRO-GIL et al., 2020).

Outro experimento que tratou da meditação amor-bondade foi realizado por Fredrickson et al. (2008) com mais de 200 empregados de uma grande empresa de tecnologia em Detroit. Metade dos participantes compôs o grupo que realizou as tarefas e a outra, o grupo de controle. Tais tarefas se traduziram em seis sessões de uma hora de meditação ministradas por um especialista e, como resultado, os indivíduos obtiveram mudanças nas experiências diárias de emoções que possibilitam a construção de recursos para uma vida mais gratificante e com menos sintomas depressivos. Exemplo dessas emoções positivas que trazem os benefícios da autoaceitação, estabelecimento de relações construtivas, satisfação com a vida e senso de propósito são: amor, diversão, alegria, gratidão, admiração, contentamento, esperança, orgulho e interesse.

Congruente com os apontamentos do estudo acima está a pesquisa de Kok et al. (2013), os quais recrutaram 65 pessoas para examinarem a relação entre a meditação do amor-bondade e o estresse. A divisão foi aleatória e formada pelos grupos da lista de espera e das seis aulas semanais de meditação, tendo havido uma medição quanto à variabilidade dos batimentos

\section{POLÊM!CA $\mid$ LABORE}

Polêmica - Revista Eletrônica da Uerj - Rua São Francisco Xavier, 524, $1^{\circ}$ andar bloco D, sl.1001 • Tels.: +55 21 2334-4088 / 4087 • http://www.e-publicacoes.uerj.br/index.php/polemica/index http://www.labore.uerj.br • laboreuerj@yahoo.com.br 
cardíacos, checando-se o quão tonificado ou responsivo estava o nervo vago de cada participante. Tal medição colabora com a compreensão das conexões entre os fatores de interação social, altruísmo, saúde do coração e sistema imunológico. Os pesquisadores concluíram que aqueles que fizeram as aulas de meditação apresentaram maior sensação de conexão com os outros, aumento em suas emoções positivas e melhora na função vagal.

Além dos estudos citados, é interessante destacar colocações de Mikulincer e Shaver (2007) que apontam semelhanças entre práticas de meditação da compaixão e as induções de segurança, baseadas na teoria do apego. Em seu estudo para redução de preconceito e promoção de compaixão, altruísmo, gratidão e perdão, obtiveram como resultado uma maior tolerância e compaixão, ao fazerem uso da indução de segurança (MIKULINCER.; SHAVER, 2001, 2005). Para tal, os autores (MIKULINCER; SHAVER, 2001) apresentaram uma técnica de priming ('apego seguro-primário'), na qual se estimula o indivíduo a refletir sobre um relacionamento seguro, ressaltando a disponibilidade de uma figura confiável.

Em relação aos estilos de apego, Gillath, Shaver e Mikulincer (2005) encontraram indícios de que o aumento da segurança do sistema comportamental influencia o funcionamento do sistema de cuidado compassivo. Assim, pensa-se em formas de seguir nessa direção rumo à segurança do apego e à compaixão efetiva consequente, podendo ser citadas duas. A primeira, as crianças serem cuidadas de forma a aumentar sua sensação de segurança; a segunda, uma constante lembrança dos momentos em que se teve apoio, ou imaginar situações semelhantes, podendo recorrer-se a histórias religiosas ou obras de arte como inspiração (OMAN; THORESEN, 2003). Uma vez que uma pessoa se beneficiou do cuidado de outra, ou imaginou e emulou os tipos de cuidado e preocupação demonstrados por cuidadores ou figuras religiosas, retomar mentalmente essas recordações parece ter efeito de aumento de segurança (GILLATH; SHAVER; MIKULINCER, 2005; JINPA, 2016). O mesmo resultado é encontrado, através da exposição a imagens de exemplos de bondade amorosa (GILLATH; SHAVER; MIKULINCER, 2005).

Outras contribuições de Mikulincer e Shaver (2007) estão relacionadas à psicologia positiva, a qual ressalta que uma base psicológica segura ajuda a enfrentar obstáculos e se manter equânime diante do estresse, enquanto segue-se o crescimento e a autorrealização. Seriam as experiências de receber amor, aceitação e apoio as formas mais importantes de proteção pessoal e autoconfiança. Outra consequência, em tese, de mais segurança e

\section{POLÊM!CA $\mid$ LABORE}

Polêmica - Revista Eletrônica da Uerj - Rua São Francisco Xavier, 524, $1^{\circ}$ andar bloco D, sl.1001 • Tels.: +55 21 2334-4088 / 4087 • http://www.e-publicacoes.uerj.br/index.php/polemica/index http://www.labore.uerj.br • laboreuerj@yahoo.com.br 
"ampliação" da disponibilidade de figuras de apego é melhorar o funcionamento do sistema de cuidado, maior tolerância intergrupal e mais disposição para prestar cuidados a outros.

Mais contribuições são as de Baldwin, Bandarian-Balooch e Adams (2020) que buscaram uma forma de reduzir a resposta fisiológica que o indivíduo experimenta, quando interpreta a compaixão como algo ameaçador. Para registrar a resposta fisiológica, foram coletados - no início e durante os exercícios - dados sobre a variabilidade da frequência cardíaca. Então, propuseram e testaram uma metodologia que procurou aumentar os níveis de estado de apego seguro, contando com 68 participantes no total, incluso o grupo controle. Foram aplicados dois exercícios de imagens mentais com foco na compaixão. Verificou-se que entre os indivíduos classificados como de apego predominantemente ansioso e evitativo houve diminuição na variabilidade da frequência cardíaca, indicando uma maior tendência a respostas de ameaça à imagem com foco na compaixão. Depois de induzido um 'apego seguro-primário' (MIKULINCER; SHAVER, 2001), essa variabilidade aumentou, evidência de respostas autocalmantes e menor experenciação de ameaça frente à segunda imagem focada na compaixão. Assim, os inseguramente apegados provavelmente demandarão suporte a mais para aumentar sua segurança de apego, antes que realizem atividades baseadas na compaixão e encontrem resultado efetivo. Para esse tipo de população, tais exercícios podem resultar em medo e levar à evitação. Tem-se, por fim, que as respostas às ameaças à compaixão podem ser reduzidas com o uso de técnicas baseadas na teoria do apego.

Por outro lado, Caldwell e Shaver (2015) não trabalharam com compaixão, mas com meditação e apego. Eles fizeram um estudo com mulheres que foram maltratadas na infância e confirmaram que a o apego ansioso tinha conexão com a ruminação e a emoção negativa; o apego evitativo, com a supressão de emoções e falta de clareza emocional; enquanto ambos, com a desregulação emocional e níveis mais baixos de atenção plena. O estudo contou com grupo controle e obteve os seguintes resultados: as mulheres que fizeram as atividades relacionadas à atenção plena apresentaram melhorias significativas na ruminação, supressão de emoções, clareza de emoções, regulação de emoções e atenção plena; mudanças vinculadas aos pensamentos e emoções dos participantes em relação ao apego.

Igualmente, Dudley et al. (2018) realizaram um estudo voltado para atenção plena, porém pensado numa perspectiva de psicose. Eles associaram o estilo de apego à relação com construtos de atenção plena às vozes, autocompaixão e angústia de ouvi-las. A autocompaixão

\section{POLÊM!CA | LABORE}

Polêmica - Revista Eletrônica da Uerj - Rua São Francisco Xavier, 524, $1^{\circ}$ andar bloco D, sl.1001 • Tels.: +55 21 2334-4088 / 4087 • http://www.e-publicacoes.uerj.br/index.php/polemica/index http://www.labore.uerj.br • laboreuerj@yahoo.com.br 
e o apego seguro têm sido associados à melhoria de áreas do bem-estar psicológico, o que ajuda a estar diante das vozes sem julgamentos e aceitá-las melhor (diminuindo a angústia). Assim, fazendo-se uso do método transversal online, 108 pessoas (que ouviam vozes) completaram as escalas Self-Compassion Scale, Southampton Mindfulness of Voices Questionnaire, Relationships Questionnaire e Hamilton Programme for Schizophrenia Voices Questionnaire. Os pesquisadores perceberam que a autocompaixão e a severidade das vozes são mediadas pela atenção plena a elas, já que autocompaixão e atenção às vozes foram positivamente correlacionadas. Em contrapartida, foram negativamente correlacionadas com angústia e severidade das vozes.

Ponto a salientar é que, muitas vezes, o indivíduo vê a si próprio da mesma forma como era tratado por figuras-chave de apego, ou seja, atribui a si próprio as qualidades e os sentimentos decorrentes da maneira como era tratado, o que pode ajudar a regular a emoção (supondo tratamento com empatia e compaixão). Nesse caso, toma-se os predicados pessoais dos cuidadores "emprestados" para consolar a si mesmo (MIKULINCER; SHAVER, 2007). Ou seja, não é possível atribuir o estabelecimento de um estilo de apego à, simplesmente, genética, principalmente, posto a possibilidade de imitação dos pais pelos filhos (um processo de transmissão) e que os padrões de apego podem ser diferentes com outros indivíduos e em momentos diferentes da vida. Uma pessoa segura pode, portanto, encorajar a autorrevelação de um parceiro, sem levantar um sentimento de vulnerabilidade a mal-entendido ou rejeição da parte do outro. Então, no caso do sistema de cuidado de uma pessoa se desenvolver de forma social favorável, compaixão, bondade amorosa e a generosidade tendem a vir à tona.

No que diz respeito ao cuidador, o sofrimento do outro pode lhe provocar reações emocionais de compaixão empática e angústia pessoal (BATSON, 1991), o que ajuda a entender se deve ajudar a outra pessoa ou se afastar, para evitar seus próprios sentimentos negativos. Na compaixão, deve-se aliviar as necessidades do sofredor (JINPA, 2016; BATSON, 1991), sem qualquer recompensa direta (cuidado incondicional), mas na angústia pessoal, focase no próprio desconforto (BATSON, 1991). Provavelmente, somente se esse desconforto for aliviado ajudando o outro, o cuidador o fará e em condições de "fuga fácil". Quando seu sofrimento pode ser reduzido de outra forma, não há ajuda, ou seja, o sofrimento pessoal não motiva a colaboração empática.

\section{POLÊM!CA $\mid$ LABORE}

Polêmica - Revista Eletrônica da Uerj - Rua São Francisco Xavier, 524, $1^{\circ}$ andar bloco D, sl.1001 • Tels.: +55 21 2334-4088 / 4087 • http://www.e-publicacoes.uerj.br/index.php/polemica/index http://www.labore.uerj.br • laboreuerj@yahoo.com.br 
Para Mikulincer e Shaver (2007), existem diversas evidências de que o sistema de apego afeta a operação do sistema de cuidado, podendo haver uma conexão circular recíproca entre a segurança do apego e o cuidado compassivo e generoso. Mikulincer et al. (2001) realizaram cinco estudos que avaliaram os efeitos da ativação crônica e contextual do sistema de apego nas reações às necessidades dos outros. Para tal, aos participantes foi demandado que resgatassem memórias, lessem uma história, encarassem uma imagem de quem os apoiava, ou ficassem diante de palavras que remetessem à proximidade, de maneira subliminar. Depois, houve uma comparação com o surgimento de temas neutros, afeto positivo ou esquemas de insegurança de apego para, a seguir, serem avaliados relatos de empatia e sofrimento pessoal ou a acessibilidade de memórias de empatia e sofrimento pessoal. Encontraram, então, indícios de que a teoria do apego é relevante para explicar as reações às necessidades dos outros, mediante os resultados apontando para o estímulo da segurança do apego como fortalecedor de empatia e inibidor de sofrimento pessoal. Além disso, segundo os resultados, pessoas cujos estilos de apego predominantes foram classificados como evitativos ou ansiosamente apegados fizeram autorrelatos inversamente relacionados à empatia. Os autorrelatos das pessoas de estilo ansiosamente apegado apontavam sofrimento pessoal, preocupação consigo aumentada e sentimento de angústia, provavelmente, despertado pela empatia, mas sem resultar na motivação para a ação. Já os de estilo evitativo teriam reduzida a sua capacidade de resposta às necessidades alheias (MIKULINCER et al., 2001).

Vale destacar mais conclusões do estudo, que incluem o aumento da segurança do apego (não apenas aumento do afeto positivo) ter fortalecido a compaixão e inibido o sofrimento pessoal em relação ao sofrimento dos outros. Assim, o indivíduo torna-se capaz de despertar seu sistema comportamental de cuidado, atentar-se para sofrimento alheio, colocar-se no lugar do angustiado e, finalmente, realizar atitude altruísta. Esse processo se justifica, pois o seguramente apegado já sente segurança e proteção, não tendo demanda de ajudar ao outro com esse intuito, mas sim, tem energia e atenção para serem usadas pelo sistema de cuidado, permitindo que seja empático em relação ao sofrimento dos outros. Percebe-se que o apego seguro pode ser associado à maior compaixão, maior disposição para ajudar e mais realização de atividades altruístas. Além disso, existem evidências de que a segurança do apego neutraliza alguns dos motivos egoístas subjacentes à relutância das pessoas - cujo apego é predominantemente evitativo - em ajudar (MIKULINCER et al., 2001).

\section{POLÊM!CA $\mid$ LABORE}


Ainda, as diferentes formas de lidar com os sentimentos (FOSHA; SIEGEL; SOLOMON, 2009) e com a compaixão (JINPA, 2016) estão ligadas aos mecanismos de defesa (FOSHA; SIEGEL; SOLOMON, 2009) desenvolvidos para lidar com as adversidades advindas de determinadas vivências (FOSHA; SIEGEL; SOLOMON, 2009; JINPA, 2016). Dentre elas, o sistema afiliativo (ou de cuidado) estabelecido durante os primeiros anos de vida que, quando de acordo com o ideal, é associado à segurança, proximidade e contentamento, afinal, recebese dos cuidadores conforto, tranquilidade e segurança, sentimentos associados à produção natural de opióides endógenos e de hormônios como a ocitocina (JINPA, 2016). Essas relações nos primeiros momentos de vida são responsáveis por criarem memórias emocionais que dificilmente serão esquecidas, dando-se origem à capacidade de se acalmar por meio de um processo de lembrança emocional.

Suposto que se construa um apego seguro, acredita-se na possibilidade de estar em segurança, afinal, é uma sensação anteriormente visitada, e tem-se ao que recorrer em situações de estresse, ou seja, o estilo de apego tem influência na regulação emocional. Tal regulação, por sua vez, influencia o limiar de autocompaixão na idade adulta e, caso não tenha se formado esse tipo de apego, há necessidade de "construir aquela sensação de calor e segurança a partir do zero durante a idade adulta" (JINPA, 2016, p. 86). É possível, todavia, fazer uso da própria experiência do sofrimento e da capacidade de sentir compaixão, como instrumentos na meditação da autocompaixão, direcionando esse sentimento para si, justamente, por não ter tido essas vivências cruciais anteriormente.

Por fim, as pesquisas e estudiosos aqui mencionados de alguma forma fizeram alguma relação entre estilos de apego e técnicas que o alteram, apego e suas influências, meditação de amor bondade e seus benefícios, meditação da compaixão (budista) e teoria do apego, teoria do apego e compaixão, meditação e teoria do apego, abordaram intervenções baseadas na compaixão ou na teoria do apego. Por essa razão, foram selecionados, na tentativa de esclarecer a dúvida: a prática da meditação da compaixão pode colaborar com a construção de um estilo de apego mais seguro e, portanto, vantajoso nas relações interpessoais?

\section{POLÊM!CA $\mid$ LABORE}

Polêmica - Revista Eletrônica da Uerj - Rua São Francisco Xavier, 524, $1^{\circ}$ andar bloco D, sl.1001 • Tels.: +55 21 2334-4088 / 4087 • http://www.e-publicacoes.uerj.br/index.php/polemica/index http://www.labore.uerj.br • laboreuerj@yahoo.com.br 


\section{Conclusões}

Neste artigo, primeiramente procurou-se definir apego, suas classificações e forma de fazê-lo, suas implicações e sua influência na vida do indivíduo. Em seguida, buscou-se entender o que é meditação, incluindo diferenças e funções, e, de forma mais aprofundada, investigouse as práticas e os benefícios da meditação voltada para a compaixão. Por fim, foram reunidos e examinados estudos anteriores que fizeram essa correlação com o intuito de verificar se a prática da meditação compassiva pode influenciar na reestruturação do estilo de apego predominante nas relações, visando alcançar um apego seguro.

Para tal, mencionou-se um estudo de Mikulincer et al. (2001) que usou uma técnica de priming (apego seguro-primário), prática que inclui ter em mente uma figura confiável (MIKULINCER; SHAVER, 2001), e os métodos que Mikulincer e Shaver (2001, 2005, 2007) recorreram para chegar à tolerância e compaixão. Assim como é feito na meditação da compaixão, esses autores buscaram estimular o sentimento de amor incondicional e enfatizar a segurança. Ambas as práticas ainda têm em comum suas naturezas sociais e o fomentar da compaixão e, em razão das paridades entre elas, faz sentido pensar que estudos comprovando a eficácia da técnica de priming favorecem a validação da meditação da compaixão para a mesma função.

Ademais, Bowlby (1989), Mikulincer e Shaver (2007) são pesquisadores que também compartilham ideias relacionadas aos cuidados primários que resultam no desenvolvimento de determinado estilo de apego, que, não sendo definitivo, pode ser modificado a partir de outras relações. Os últimos mencionam o fenômeno da imitação e a possível habilidade de uma pessoa segura encorajar a autorrevelação de outra, sem estimular efeitos negativos, podendo despertar sentimentos de compaixão, bondade amorosa e generosidade. Todavia, para que haja uma interação harmoniosa com o outro, é necessário estar a par dos pontos de vista, objetivos e sentimentos dele (BOWLBY, 1989), o que podemos vincular à empatia e, por consequência, à compaixão. Bowlby (1989) acredita na tendência a tratar os outros da mesma forma como somos tratados, havendo, portanto, chances da passagem do estilo de apego dos pais para as próximas gerações, de maneiras sucessivas.

Ainda a respeito das influências da teoria do apego, retoma-se o fato de o aumento da segurança provavelmente intervir no funcionamento do sistema de cuidado, tornando-o mais compassivo (GILLATH; SHAVER; MIKULINCER, 2005). Propõe-se reaver, também, formas

\section{POLÊM!CA $\mid$ LABORE}

Polêmica - Revista Eletrônica da Uerj - Rua São Francisco Xavier, 524, $1^{\circ}$ andar bloco D, sl.1001 • Tels.: +55 21 2334-4088 / 4087 • http://www.e-publicacoes.uerj.br/index.php/polemica/index http://www.labore.uerj.br • laboreuerj@yahoo.com.br 
de ir ao encontro da segurança do apego e da consequente compaixão. Duas delas são as crianças terem a sensação de segurança aumentada e uma constante lembrança dos momentos em que foi experienciado apoio - efetivo ou imaginário - recorrendo a figuras religiosas e obras de arte (OMAN; THORESEN, 2003). Recordar mentalmente essas imagens parece ter efeito de aumento de segurança (GILLATH; SHAVER; MIKULINCER, 2005; JINPA, 2016), assim como ser exposto a figuras exemplos de bondade amorosa (GILLATH; SHAVER; MIKULINCER, 2005). Quanto aos artifícios para acessar esses sentimentos, se justificam porque uma pessoa mais seguramente apegada e com maior disponibilidade das figuras de apego tem melhor funcionamento do sistema de cuidado, está mais sujeito a aceitar tal atenção e tem maior tolerância intergrupal (MIKULINCER; SHAVER, 2007).

A meditação amor bondade beneficia ainda mais as relações de grupo, pois a prática proporciona maior sensação de conexão com os outros, aumenta as emoções positivas e melhora a função vagal (KOK et al., 2013). Além disso, autores relatam a conquista de melhorias nas emoções positivas (que trazem os benefícios da autoaceitação, estabelecimento de relações construtivas, satisfação com a vida e senso de propósito) e, portanto, uma vida mais gratificante e com menos sintomas depressivos (FREDRICKSON et al., 2008).

Sobre o elo entre a busca por um apego seguro e compaixão, técnicas advindas da teoria do apego podem reduzir as respostas às ameaças à compaixão (BALDWIN; BANDARIANBALOOCH; ADAMS, 2020) e o sentimento mencionado é uma possível ferramenta terapêutica para tratamento de pacientes com apego inseguro (KRASUSKA et al., 2017apud NAVARROGIL et al., 2020). Ainda nessa temática, vale considerar que o sofrimento pessoal (angústia) leva à dificuldade de exercer a compaixão, não motivando a colaboração empática (BATSON, 1991).

Por outro lado, uma prática que estimule a segurança do apego pode fortalecer a empatia e inibir o sofrimento pessoal, enquanto os estilos de apego ansioso e evitativo estão inversamente relacionados à empatia e o ansioso, positivamente relacionado ao sofrimento pessoal. Percebe-se, portanto, que a teoria do apego é relevante para explicar as reações às necessidades dos outros (MIKULINCER et al., 2001), sendo um indicativo o aumento da segurança do apego fortalecer a compaixão e inibir o sofrimento pessoal em relação ao sofrimento alheio. Isso ocorre, pois a autoproteção defensiva se reduz e, assim, pode-se estimular uma compaixão elevada sem interesses pessoais envolvidos. Verifica-se que

\section{POLÊM!CA $\mid$ LABORE}

Polêmica - Revista Eletrônica da Uerj - Rua São Francisco Xavier, 524, $1^{\circ}$ andar bloco D, sl.1001 • Tels.: +55 21 2334-4088 / 4087 • http://www.e-publicacoes.uerj.br/index.php/polemica/index http://www.labore.uerj.br • laboreuerj@yahoo.com.br 
seguramente apegados já se sentem protegidos, tendo capacidade para despertar seu sistema comportamental de cuidado, atentar-se para sofrimento alheio, colocar-se no lugar do indivíduo angustiado e realizar atitude altruísta. Assim, percebe-se que pessoas com apego seguro podem apresentar maior compaixão, maior disposição para ajudar e mais realização de atividades altruístas. Portanto, caso o apego do indivíduo não seja seguro, há necessidade de construí-lo (JINPA, 2016) com a própria experiência do sofrimento e a capacidade de sentir compaixão, sendo um meio aplicar a técnica da meditação amor-bondade direcionando esse sentimento para si.

Outrossim, quando se relaciona meditação e teoria do apego, pesquisas têm investigado a atenção plena, que resulta em melhorias significativas na ruminação, supressão de emoções, clareza de emoções, regulação de emoções e atenção. Mudanças essas vinculadas aos pensamentos e emoções relacionadas ao apego (CALDWELL; SHAVER, 2015) e, por ser igualmente uma forma de meditação e envolver a atenção plena, faz sentido pensar que a prática da meditação da autocompaixão pode ter efeitos semelhantes. Mais evidências são trazidas por Dudley et al. (2018), que verificaram que o estilo de apego e a atenção plena se relacionam com escutar vozes na psicose, com sentir autocompaixão e com a angústia de ouvi-las. Em seus estudos, observou-se que a atenção plena funciona como mediadora, enquanto a autocompaixão e a atenção às vozes foram positivamente correlacionadas entre si e negativamente correlacionadas com angústia e severidade das vozes.

Neste artigo, também foram apresentadas intervenções baseadas na compaixão e exposto que diversas delas evidenciaram efeito na melhora da satisfação com a vida e no lidar com o sofrimento (KIRBY, 2017). Mais ainda, foram apontadas intervenções baseadas na teoria do apego, como a ABCT, que tem um claro vínculo com a meditação da compaixão, intencional ou não. Ou seja, ABCT é baseado na teoria do apego, mas seus aspectos são facilmente comparáveis à meditação amor bondade, com o acréscimo diferencial de ajudarem na identificação do próprio estilo de apego predominante e na percepção de sua influência nos seus relacionamentos interpessoais atuais. Não é difícil concluir que, provavelmente, alguns dos resultados obtidos ao aplicar o ABCT também poderiam ser alcançados apenas com o emprego da técnica meditativa. Em adultos saudáveis e cujo apego não era desorganizado, são eles: reduzir significativamente os níveis de ansiedade e evitação; aumentar consideravelmente o estilo de apego seguro; melhora na autocompaixão, benevolência, autojulgamento, humanidade

\section{POLÊM!CA | LABORE}

Polêmica - Revista Eletrônica da Uerj - Rua São Francisco Xavier, 524, $1^{\circ}$ andar bloco D, sl.1001 • Tels.: +55 21 2334-4088 / 4087 • http://www.e-publicacoes.uerj.br/index.php/polemica/index http://www.labore.uerj.br • laboreuerj@yahoo.com.br 
comum, atenção plena, superidentificação, observação, no agir com consciência, no não julgamento da experiência interior e na não reatividade à experiência interior; diminuir a evitação experiencial e o distúrbio psicológico (NAVARRO-GIL et al., 2020).

\section{Considerações finais}

$\mathrm{Na}$ análise dos trabalhos selecionados não foram identificadas pesquisas associando especificamente meditação da compaixão e teoria do apego, tornando evidente a necessidade de investigações científicas sobre essa temática, cuja importância se justifica por razões interpessoais, voltadas ao bem-estar pessoal e à convivência em uma sociedade mais compassiva. O presente estudo não apontou evidências referentes à hipótese de que a meditação da compaixão resulta em uma mudança positiva no estilo de apego, todavia, reuniu informações de universos diferentes e com pontos em comum, sendo, talvez, uma forma preliminar de contribuir para

novas pesquisas com o mesmo objetivo. Em suma, a hipótese não foi refutada, mas deparouse com indícios de confirmação, ainda que insuficientes.

Finalmente, após as leituras, análises, comparações e considerações aqui registradas acredita-se que foram corroborados diversos benefícios da autocompaixão, compaixão e práticas meditativas, além de certa associação com a teoria do apego e, por isso, uma temática relevante a ser investigada. A prática da meditação é cientificamente muito respaldada e estudada (como algo positivo ou, no mínimo, neutro para os praticantes), porém, investigada há um tempo relativamente recente, não tendo sido explorado todo o seu potencial e ainda não registrados cientificamente todos os benefícios proporcionados por ela. Portanto, sugere-se mais estudos experimentais e nos moldes da ciência para ainda maior validação da prática milenar.

\section{Referências}

AINSWORTH, M. S.; BLEHAR, M. C.; WATERS, E.; WALLS, S. Patterns of attachment: A psychological study of the strange situation. Hillsdale, NJ: Lawrence Erlbaum, 1978.

AMATO, J. L.; BARBOSA, P. P.; GEOCZE, N. L. D.; CUNHA, E. A. P. F. W. da; CASSANTI, A. C.; POLCINO, M. D. G.; ZANINI, F. A.; RORATO, C. B.; OLIVEIRA, G.; CISZEWSKI, A. C.; OLIVEIRA, R. M. J. de; LEITE, J. R. Os benefícios da meditação Loving-Kindness. Revista Brasileira de Medicina de Família e Comunidade, Rio de Janeiro, v. 7, n. 1, p. 66, jun. 2012. Disponível em: https://rbmfc.org.br/rbmfc/article/view/613. Acesso em: 20 fev. 2021.

\section{POLÊM!CA $\mid$ LABORE}

Polêmica - Revista Eletrônica da Uerj - Rua São Francisco Xavier, 524, $1^{\circ}$ andar bloco D, sl.1001 • Tels.: +55 21 2334-4088 / 4087 • http://www.e-publicacoes.uerj.br/index.php/polemica/index http://www.labore.uerj.br • laboreuerj@yahoo.com.br 
BALDWIN, S.; BANDARIAN-BALOOCH, S.; ADAMS, R. Attachment and compassion-threat: Influence of a secure attachment-prime. Psychology and Psychotherapy - Theory Res. Pract., v. 93, n. 3, p. 520-536, set. 2020. DOI: https://doi.org/10.1111/papt.12244.

BATSON, C. D. The altruism question: Toward a social psychological answer. Hillsdale, NJ: Erlbaum, 1991.

BEEBE, B.; LACHMANN, F. M. The contribution of mother-infant mutual influence to the origins of self-and object representations. Psychoanalytic Psychology, v. 5, n. 4, p. 305-337, jan. 1988.

BISHOP, S. R.; LAU, M.; SHAPIRO, S.; CARLSON, L.; ANDERSON, N. D.; CARMODY, J.; DEVINS, G. Mindfulness: A proposed operational definition. Clinical Psychology: Science and Practice, v. 1, n. 3, p. 230241, 2004. DOI: https://doi.org/10.1093/clipsy.bph077.

BOWLBY, J. The making and breaking of affectional bonds. I. Aetiology and psychopathology in the light of attachment theory. An expanded version of the Fiftieth Maudsley Lecture, delivered before the Royal College of Psychiatrists, 19 November 1976. The British journal of psychiatry: the journal of mental science, v. 130, n. 3, mar. 1977. DOI: https://doi.org/10.1192/bjp.130.3.201.

BOWLBY, J. Attachment and Loss: Loss, sadness, and depression. New York: Basic Books, 1980. V. 2.

BOWLBY, J. Attachment and Loss: Attachment. 2nd. ed. New York: Basic Books, 1969/1982. V. 1.

BOWLBY, J. Uma base segura: Aplicações clínicas da teoria do apego. Porto Alegre: Artes Médicas, 1989.

BOWLBY, J. Post-script. In: PARKES, C. M.; STEVENSON-HINDE, J.; MARRIS, P. (Ed.). Attachment across the life cycle. London: Routledge, 1991. p. 293-297.

BRANDON, C.; SHANNON, M.C.; LAURA, S. Is compassion for others stress buffering?Consequences of compassion and social support for physiological reactivity to stress. Journal of Experimental Social Psychology, v. 46, n. 5, p. 816-823, 2010. DOI: https://doi.org/10.1016/j.jesp.2010.04.008.

CALDWELL, J. G.; SHAVER, P. R. Promoting attachment-related mindfulness and compassion: A wait-listcontrolled study of women who were mistreated during childhood. Mindfulness, v. 6, n. 3, p. 624-636, 2015. DOI: https://doi.org/10.1007/s12671-014-0298-y.

CAMPAGne, D. M. Teoría y fisiología de la meditación. Cuadernos de Medicina Psicosomática y Psiquiatríade Enlace, n. 69-70, p. 15-30, 2004.

CARDOSO, R. Medicina e meditação: um médico ensina a meditar. 2. ed. São Paulo: MG Editores, 2005.

CARDOSO, R.; de SOUZA, E.; CAMANO, L.; LEITE, J. R. Meditation in health: an operational definition. Brain research protocols, v. 14, n. 1, p. 58-60, nov. 2004. DOI:

https://doi.org/10.1016/j.brainresprot.2004.09.002.

CASSIDY, J. Emotion regulation: Influence of attachment relationships. Monographs of the Society for Research in Child Development, v. 69, n. 2-3, p. 228-249, 1994.

DAVIDSON, R. J.; GOLEMAN, D. J.; SCHWARTZ, G. E. Attentional and affective concomitants of meditation: A cross-sectional study. Journal of Abnormal Psychology, v. 85, n. 2, p. 235-238, 1976. DOI: https://doi.org/10.1037/0021-843X.85.2.235.

DAVIDSON, R. J.; GOLEMAN, D. J. The role of attention in meditation and hypnosis: A psychobiological perspective on transformations of consciousness. The International Journal of Clinical and Experimental Hypnosis, v. 25, n. 4, p. 291-308, out. 1977.

DUDLEY, J.; EAMES, C.; MULLIGAN, J.; FISHER, N. Mindfulness of voices, self-compassion, and secure

\section{POLÊM!CA $\mid$ LABORE}

Polêmica - Revista Eletrônica da Uerj - Rua São Francisco Xavier, 524, $1^{\circ}$ andar bloco D, sl.1001 • Tels.: +55 21 2334-4088 / 4087 • http://www.e-publicacoes.uerj.br/index.php/polemica/index http://www.labore.uerj.br • laboreuerj@yahoo.com.br 
attachment in relation to the experience of hearing voices. The British Journal of Clinical Psychology, v. 57, n. 1, p. 1-17, mar. 2018. DOI: https://doi.org/10.1111/bjc.12153.

EKMAN, P. Moving Toward Global Compassion. San Francisco: Paul Ekman Group, 2014.

EMDE, R. N. Development terminable and interminable: I. Innate and motivational factors from infancy. The International Journal of Psychoanalysis, v. 69, n. 1, p. 23-42, 1988.

FOSHA, D.; SIEGEL, D.; SOlOMON, M. (Ed.). The Healing Power of Emotion: Affective neuroscience, development \& clinical practice. New York: W. W. Norton \& Company, 2009.

FREDRICKSON, B. L.; COHN, M. A.; COFFEY, K. A.; PEK, J.; FINKEL, S. M. Open hearts build lives: positive emotions, induced through loving-kindness meditation, build consequential personal resources. Journal of Personality and Social Psychology, v. 95, n. 5, p. 1045-1062, 2008. DOI: https://doi.org/10.1037/a0013262.

GILBERT, P. Compassion and cruelty: A biopsychosocial approach. In: GILBERT, P. (Ed.). Compassion: Conceptualization, research and use in psychotherapy. New York: Routledge, 2005. p. 9-74.

GILLATH, O.; SHAVER, P. R.; MIKULINCER, M. An attachment-theoretical approach to compassion and altruism. In: GILBERT. P. (Ed.). Compassion: Conceptualization, research and use in psychotherapy. New York: Routledge, 2005. p. 121-147.

GOETZ, J. L.; KELTNER, D.; SIMON-THOMAS, E. Compassion: an evolutionary analysis and empirical review. Psychological bulletin, v. 136, n. 3, p. 351-374, 2010. DOI: https://doi.org/10.1037/a0018807.

GOLEMAN, D. The meditative mind: the varieties of meditative experience. New York: G.P. Putnam's Sons, 1988.

JINPA, T. Um coração sem medo. Rio de Janeiro: Sextante, 2016.

KABAT-ZINN, J. Mindfulness-based interventions in context: Past, present, and future. Clinical Psychology: Science and Practice, v. 10, n. 2, p. 144-156, 2003. DOI: https://doi.org/10.1093/clipsy.bpg016.

KIRBY, J. N. Compassion interventions: The programmes, the evidence, and implications for research and practice. Psychology and psychotherapy, v. 90, n. 3, p. 432-455, set. 2017. DOI: https://doi.org/10.1111/papt.12104.

KISSEN, M. Affect, object, and character structure. Madison, CT: International Universities Press, 1995.

KOK, B. E.; COFFEY, K. A.; COHN, M. A.; CATALINO, L. I.; VACHARKULKSEMSUK, T.; ALGOE, S. B.; BRANTLEY, M.; FREDRICKSON, B. L. How Positive Emotions Build Physical Health: Perceived Positive Social Connections Account for the Upward Spiral Between Positive Emotions and Vagal Tone. Psychological Science, v. 24, n. 7, p. 1123-1132, maio 2013. DOI: https://doi.org/10.1177/0956797612470827.

LACHMANN, F. M.; BEEBE, B. Reformulations of early development and transference: Implications for psychic structure formation. In: BARRON, J. W.; EAGLE, M. N.; WOLITZKY, D. L (Ed). Interface of psychoanalysis and psychology. American Psychological Association, 1992. p. 133-153. DOI: https://doi.org/10.1037/10118-005.

LAYOUS, K.; NELSON, S. K.; OBERLE, E.; SCHONERT-REICHL, K. A.; LYUBOMIRSKY, S. Kindness counts: prompting prosocial behavior in preadolescents boosts peer acceptance and well-being. PloS One, v. 7, n. 12, dez. 2012. DOI: https://doi.org/10.1371/journal.pone.0051380.

MAIN, M. Recent studies in attachment: Overview with selected implications for clinical work. In: GREENBERG, S.; MUIR, R.; KERR, J. (Ed.). Attachment theory: Social, developmental and clinical perspectives. Hillsdale, NJ: Analytic Press, 1995. p. 407-472.

\section{POLÊM!CA $\mid$ LABORE}

Polêmica - Revista Eletrônica da Uerj - Rua São Francisco Xavier, 524, $1^{\circ}$ andar bloco D, sl.1001 • Tels.: +55 21 2334-4088 / 4087 • http://www.e-publicacoes.uerj.br/index.php/polemica/index http://www.labore.uerj.br • laboreuerj@yahoo.com.br 
MAIN, M., HESSE, E. The insecure disorganized/disoriented attachment pattern in infancy: Precursors and sequelae. In: GREENBERG, M. T.; CICHETTI, D.; CUMMINGS, E. M. (Ed.). Attachment in the preschool years: Theory, research and intervention. Chicago: University of Chicago Press, 1990. p. 161-182.

MENEZES, C. B.; DELL'AGLIO, D. D. Os efeitos da meditação à luz da investigação científica em Psicologia:revisão de literatura. Psicologia: Ciência e Profissão, Brasília, v. 29, n. 2, p. 276-289, 2009. DOI: https://doi.org/10.1590/S1414-98932009000200006.

MIKULINCER, M.; GILLATH, O.; HALEVY, V.; AVIHOU, N.; AVIDAN, S.; ESHKOLI, N. Attachment theory and reactions to others' needs: Evidence that activation of the sense of attachment security promotes empathic responses. Journal of Personality and Social Psychology, v. 81, n. 6, p. 1205-1224, 2001. DOI: https://doi.org/10.1037/0022-3514.81.6.1205.

MIKULINCER, M.; SHAVER, P. R. Attachment theory and intergroup bias: Evidence that priming the secure base schema attenuates negative reactions to out-groups. Journal of Personality and Social Psychology, v. 81, n. 1, p. 97-115, 2001. DOI: https://doi.org/10.1037/0022-3514.81.1.97.

MIKULINCER, M.; SHAVER, P. R. Attachment security, compassion, and altruism. Current Directions in Psychological Science, v. 14, n. 1, p. 34-38, fev. 2005. DOI: https://doi.org/10.1111/j.0963-7214.2005.00330.x.

MIKUlinCER, M.; SHAVER, P. R. Attachment Patterns in Adulthood: structure, dynamics and change. New York: Guilford Press, 2007.

NARANJO, C. Entre meditação e psicoterapia. Rio de Janeiro: Vozes, 2005.

NAVARRO-GIL, M.; LOPEZ-DEL-HOYO, Y.; MODREGO-ALARCÓN, M.; MONTERO-MARIN, J.; VAN GORDON, W.; SHONIN, E.; GARCIA-CAMPAYO, J. Effects of attachment-based compassion therapy (ABCT) on self-compassion and attachment style in healthy people. Mindfulness, v. 11, p. 51-62, jan. 2020. DOI: https://doi.org/10.1007/s12671-018-0896-1.

NEFF, K. D.; GERMER, C. K. A pilot study and randomized controlled trial of the mindful self-compassion program. Journal of Clinical Psychology, v. 69, n. 1, p. 28-44, jan.2013. DOI: https://doi.org/10.1002/jclp.21923.

OMAN, D.; THORESEN, C. E. Spiritual modeling: A key to spiritual and religious growth? International Journal for the Psychology of Religion, v. 13, n. 3, p. 149-165, 2003. DOI: https://doi.org/10.1207/S15327582IJPR1303_01.

SANDLER, J. The background of safety. International Journal of Psychoanalysis, v. 41, p. 352-356, 1960.

SHAPIRO, D. Meditation: Clinical and health-related applications. The Western Journal of Medicine, v. 134, n. 2, p. 141-142, 1981.

SHAPIRO, S. L.; SCHWARTZ, G. E. R.; SANTERRE, C. Meditation and Positive Psychology. In: SNYDER, C. R.; LOPEZ, S. J. (Ed.). Handbook of Positive Psychology. Cary, NC: Oxford University Press, 2005.

SLAGTER, H. A.; LUTZ, A.; GREISCHAR, L. L.; FRANCIS, A. D.; NIEUWENHUIS, S.; DAVIS, J. M.; DAVIDSON, R. J. Mental training affects distribution of limited brain resources. PLoS Biology, v. 5, n. 6, esp. 138, maio 2007. DOI: https://doi.org/10.1371/journal.pbio.0050138.

WHITE, R. W. Competence and the psychosexual stages of development. In: JONES, M. R. (Ed.). Nebraska symposium on motivation. Lincoln: University of Nebraska Press, 1960. V. 8, p. 97-141.

Recebido em: 17/06/2021.

Aceito em: 30/11/2021.

\section{POLÊM!CA $\mid$ LABORE}

Polêmica - Revista Eletrônica da Uerj - Rua São Francisco Xavier, 524, $1^{\circ}$ andar bloco D, sl.1001 • Tels.: +55 21 2334-4088 / 4087 • http://www.e-publicacoes.uerj.br/index.php/polemica/index http://www.labore.uerj.br • laboreuerj@yahoo.com.br 